\title{
Research of Level of Social Security based on PCA
}

\author{
Xiu-Zhi HE ${ }^{1}$, Chao-Qi LI ${ }^{\star}$ \\ ${ }^{1}$ South China Business College, Guangdong University of Foreign Studies, Guangzhou 510545, \\ China \\ ${ }^{2}$ Guangzhou Resident Office, CNAO, Guangzhou 510623, China \\ Email: abelnju@qq.com \\ *Corresponding author
}

Keywords: Social security, Evaluation, Factors.

\begin{abstract}
Social security system, as a social stabilizer, plays a very important role in adjusting the social income distribution, narrowing the gap between the rich and the poor, and maintaining social fairness and justice. Based on connotations of social security and regional comparisons, an index system is constructed for evaluating development and level of social security, which is mainly evaluated and measured by principal components analysis. At last, main factors that impact development and level of social security are analyzed.
\end{abstract}

\section{Introduction}

As an important part of social security system, level of social security plays important roles in steady and sustainable development of economy [1]. Internationally, it is generally measured based on ratio of social security contributions to GDP (Gross Domestic Product) [2]. However, there have been more and more complicated demands for social security with the improvement of people's living standards. When the above ratio is used for measuring level of social security, neither connotations of social security nor knowledge about all aspects of social security is comprehensively considered. In fact, the ratio-based measurement is performed according to fiscal expenditures. In such measurement, index is single-faceted that can hardly reflect actual level of social security and research conclusions would be not totally in line with pertinent policy suggestions. As a consequence, understanding of China's social security level would be not systematic or complete that it is impossible to thoroughly evaluate level of social security. In addition, there are huge gaps among areas of China [3], where regional social security systems and levels significantly differ, so it is urgent to establish a relatively perfect index system for evaluating development and level of social security.

Based on domestic and foreign scholars' research, development and level of China's social security are analyzed and evaluated by principal components analysis in combination with indexes selected according to national conditions of China and factors that impact level of China's social security, among which the factors are further explored while overall development and level of social security are confirmed.

\section{Methods and Data}

\section{Principal Components Analysis (PCA)}

Level of social security is influenced by multiple factors, which are not only associated with the level, but also interconnected. Related traditional analytical methods are unfavorable for solving problems regarding information redundancy and measurement accuracy, because index overlaying is inevitable in employing these methods. By principal components analysis, interconnected indexes about level of social security can be linearly combined to alleviate their interferences to each other. In this way, primitive variables may be reduced to a few new and representative ones and original indexes are replaced by only a few variables [4], in order that selected principal components can be not only 
suggestive of research objects' features more intensely and typically, but also cover enough information necessary for index evaluation. The principal components analysis is mainly performed according to following steps [5]:

(1) $n$ indexes chosen from m evaluation units are comprehensively evaluated. First of all, a matrix $(\mathrm{X})$ is created for operating and storing raw data.

(2) Related data and indices of X are standardized. Since this paper covers no reverse index, the data and indices are mostly standardized based on percentages, in order to obtain a standardized matrix $(G)$.

(3) Data of G are entered into SPSS13.0 for PCA, which mainly goes through several steps as follows: a, Standardize indexes and data (automatical standardization by SPSS). b, Determine number of principal components p. c, Name principal components. d. Determine scores of principal components by the following formula:

$$
F_{n}=a_{1 p} Z X_{1}+a_{2 p} Z X_{2}+\ldots+a_{n p} Z X_{n} .
$$

Where, $F_{\mathrm{n}}$ are scores of all principal components, $\mathrm{n}$ is number of original indexes, $Z X_{\mathrm{n}}$ is raw data $X_{\mathrm{n}}$, which has been processed by standardized methods, and $a_{1 i}, a_{2 i}, \ldots a_{n i}(\mathrm{i}=1,2, \ldots, p)$ is the feature vector corresponding to characteristic value of $X$ 's covariance matrix. In view that characteristic value is above 1 and cumulative variance contribution rate is higher than $80 \%$, number of principal components can be determined asp.

\section{Index System for Evaluating Level of Social Security}

As a whole, level of social security is a comprehensive index that may reflect the extent to which social security participants enjoy social security benefits. Thus, indexes related to social insurances, assistance, welfare and special care are selected. By constructing a structural index system, the level of social security in different provinces and cities is comprehensively evaluated. In this paper, 15 representative indexes are chosen for establishing an index system, as shown in Table 1. 31 provinces of China are studied in this paper, where data about related indexes have been collected from China Statistical Yearbook (2014) and China Labor Statistical Yearbook, analyzed by SPSS software.

Table 1. Index System for Evaluating Level of Social Security in China

\begin{tabular}{|c|c|c|}
\hline Target & Criteria & Indexes \\
\hline \multirow{15}{*}{\begin{tabular}{|c|} 
Index \\
System for \\
Evaluating \\
Level of \\
Social \\
Security
\end{tabular}} & \multirow{3}{*}{$\begin{array}{l}\text { Indexes on } \\
\text { Expenditures } \\
\text { for Social } \\
\text { Security } \\
\end{array}$} & Ratio of Expenditures for Social Security to GDP (X1) \\
\hline & & Ratio of Expenditures for Social Security to Fiscal Expenditures (X2) \\
\hline & & Expenditures Per Capital for Social Security (X3) \\
\hline & \multirow{5}{*}{$\begin{array}{l}\text { Indexes on } \\
\text { Social } \\
\text { Insurances }\end{array}$} & Coverage of Urban Endowment Insurance (X4) \\
\hline & & Coverage of Urban Medical Insurance (X5) \\
\hline & & Coverage of Urban Unemployment Insurance (X6) \\
\hline & & Coverage of Urban Work-related Injury Insurance (X7) \\
\hline & & Coverage of Urban Maternity Insurance (X8) \\
\hline & \multirow{4}{*}{$\begin{array}{l}\text { Indexes on } \\
\text { Social } \\
\text { Assistance }\end{array}$} & Urban Expenditure Per Capita for Minimum Living Standard (X9) \\
\hline & & Rural Expenditure Per Capita for Minimum Living Standard (X10) \\
\hline & & Expenditure Per Capita for 5 Insurances (X11) \\
\hline & & Expenditure Per Capital for Medical Assistance (X12) \\
\hline & \multirow{3}{*}{$\begin{array}{c}\text { Indexes on } \\
\text { Social } \\
\text { Welfare }\end{array}$} & $\begin{array}{l}\text { Ratio of Expenditure for Housing Security to Fiscal Expenditures } \\
\text { (X13) }\end{array}$ \\
\hline & & Ratio of Educational Expenditure to Fiscal Expenditures (X14) \\
\hline & & Dependency Ratio of Aged Population (X15) \\
\hline
\end{tabular}




\section{Results}

\section{Evaluation Results on Regional Development and Level of Social Security}

First of all, indexes are descriptively and statistically analyzed. KMO and Bartlett tests and communality analysis of principal components suggest that the index system of sampled data is quite suitable for the analysis.

After a fit test, characteristic root, contribution rate and cumulative contribution rate of principal components are determined in line with analytical requirements on the premise that the characteristic root is higher than 1 and the cumulative contribution rate is over $80 \%$. Subsequently, common factors are extracted by principal components analysis, where characteristic root of four principal components is higher than 1 , so four principal components are supposed to be extracted. To name all principal components, they are rotated by maximum variance analysis. After five iterations and convergences, the loading matrix of rotated principal components is obtained, as shown in Table 2.

Table 2. Rotated Component Matrix

\begin{tabular}{|c|c|c|c|c|}
\hline \multirow{2}{*}{ Index } & \multicolumn{4}{|c|}{ Component } \\
\cline { 2 - 5 } & 1 & 2 & 3 & 4 \\
\hline X1 & 0.016 & 0.897 & -0.169 & -0.079 \\
\hline X2 & 0.738 & 0.01 & 0.429 & -0.309 \\
\hline X3 & 0.794 & 0.533 & 0.07 & 0.216 \\
\hline X4 & 0.926 & 0.027 & 0.075 & -0.24 \\
\hline X5 & 0.875 & 0.276 & -0.16 & -0.014 \\
\hline X6 & 0.857 & -0.223 & -0.215 & -0.108 \\
\hline X7 & 0.827 & -0.356 & -0.203 & -0.048 \\
\hline X8 & 0.793 & -0.199 & -0.396 & -0.12 \\
\hline X9 & 0.786 & 0.181 & 0.115 & 0.517 \\
\hline X10 & 0.887 & 0.122 & 0.087 & 0.274 \\
\hline X11 & 0.791 & -0.089 & 0.254 & 0.349 \\
\hline X12 & 0.213 & -0.04 & -0.058 & 0.858 \\
\hline X13 & -0.627 & 0.363 & -0.401 & -0.248 \\
\hline X14 & 0.113 & -0.921 & 0.059 & -0.036 \\
\hline X15 & 0.012 & -0.238 & 0.883 & -0.045 \\
\hline Extraction Method: Principal Component Analysis. \\
\hline Rotation Method: Quartimax with Kaiser Normalization. \\
\hline a Rotation converged in 5 iterations. \\
\hline \multicolumn{5}{|l|}{} \\
\hline
\end{tabular}

From Table 2, it may be observed that the coverage of urban endowment insurances, the coverage of urban medical insurances, the coverage of urban unemployment insurances, the coverage of urban work-related injury insurances and the coverage of urban maternity risks hive a high load on the first principal component . For the ratio of social security contributions to GDP and the ratio of social security contributions to local fiscal expenditures, a high load is detected on the second principal component. The dependency ratio of aged population bears a high load on the third principal component, while urban expenditure per capita for minimum living standard, rural expenditure per capita for minimum living standard, rural expenditure per capita for five insurances and expenditure per capita for medical assistance are heavily loaded on the fourth principal component. Therefore, it may be inferred from the above analysis that the first principal component (F1) represents coverage of social security in different areas of China, the second principal component (F2) imply expenditures in social security, the third principal component (F3) indicates regional population ageing or welfare, and the fourth principal component (F4) suggest situation of social security benefits. 
Based on the above analysis, a model is built for evaluating level of China's social security, to analyze data about 15 factors of 31 provinces and determine comprehensive scores of all these provinces. Furthermore, level of social security is arranged in order and compared among 31 provinces of China, as shown in Table 3.

Table 3. Evaluation Results on Level of Social Security in Different Provinces

\begin{tabular}{|c|c|c|c|c|c|c|}
\hline Region & F1 & F2 & F3 & F4 & F & Rank \\
\hline Beijing & 1442.74 & 505.33 & 239.57 & 529.61 & 2717.25 & 1 \\
\hline Shanghai & 1287.22 & 519.65 & 184.76 & 564.96 & 2556.60 & 2 \\
\hline Tianjin & 951.97 & 250.48 & 88.93 & 915.25 & 2206.62 & 3 \\
\hline Zhejiang & 853.25 & 239.48 & 146.08 & 337.57 & 1576.38 & 4 \\
\hline Liaoning & 734.18 & 302.61 & 120.98 & 257.92 & 1415.69 & 5 \\
\hline Jiangsu & 753.33 & 219.34 & 136.38 & 269.64 & 1378.69 & 6 \\
\hline Inner Mongolia & 674.08 & 243.45 & 96.84 & 334.47 & 1348.84 & 7 \\
\hline Chongqing & 704.65 & 234.46 & 127.41 & 237.44 & 1303.97 & 8 \\
\hline Qinghai & 652.67 & 272.05 & 101.39 & 244.95 & 1271.06 & 9 \\
\hline Heilongjiang & 598.12 & 234.65 & 93.42 & 253.11 & 1179.30 & 10 \\
\hline Shaanxi & 625.73 & 179.03 & 115.06 & 243.77 & 1163.59 & 11 \\
\hline Hainan & 593.45 & 174.63 & 100.30 & 267.36 & 1135.75 & 12 \\
\hline Ningxia & 598.10 & 219.13 & 99.31 & 216.63 & 1133.17 & 13 \\
\hline Shandong & 547.25 & 148.31 & 82.10 & 321.42 & 1099.08 & 14 \\
\hline Guangdong & 588.66 & 150.79 & 106.71 & 246.79 & 1092.94 & 15 \\
\hline Xinjiang & 506.58 & 197.96 & 69.06 & 245.54 & 1019.14 & 16 \\
\hline Shanxi & 485.55 & 163.42 & 64.13 & 285.87 & 998.97 & 17 \\
\hline Tibet & 448.31 & 163.28 & 52.72 & 329.07 & 993.38 & 18 \\
\hline Fujiang & 520.75 & 127.95 & 91.34 & 238.51 & 978.55 & 19 \\
\hline Sichuan & 492.73 & 164.25 & 84.96 & 201.25 & 943.19 & 20 \\
\hline Jilin & 431.89 & 188.37 & 43.88 & 271.91 & 936.05 & 21 \\
\hline Hubei & 463.98 & 165.39 & 73.17 & 208.48 & 911.02 & 22 \\
\hline Jiangxi & 438.18 & 107.09 & 56.88 & 308.60 & 910.75 & 23 \\
\hline Hunan & 466.60 & 137.91 & 76.00 & 224.87 & 905.37 & 24 \\
\hline Anhui & 460.20 & 134.54 & 69.68 & 237.18 & 901.60 & 25 \\
\hline Hebei & 463.46 & 139.44 & 75.34 & 213.15 & 891.39 & 26 \\
\hline Gansu & 427.23 & 142.16 & 61.99 & 242.42 & 873.81 & 27 \\
\hline Guangxi & 409.89 & 103.05 & 63.84 & 242.26 & 819.04 & 28 \\
\hline Henan & 401.33 & 115.47 & 64.87 & 192.91 & 774.58 & 29 \\
\hline Yunnan & 381.60 & 124.71 & 54.52 & 195.98 & 756.81 & 30 \\
\hline Guizhou & 364.02 & 111.91 & 51.75 & 200.01 & 727.69 & 31 \\
\hline & & & & & & \\
\hline
\end{tabular}

\section{Analysis of Factors Impacting Regional Development and Level of Social Security}

According to the above analysis, it may be observed that following factors impact development and level of social security in China.

\section{(1) Coverage of social security.}

In light of the above analysis, coverage of various social insurances (namely the first principal component) has considerable impacts upon level of social security, on the grounds that social security 
system with China's characteristics must highlight the unity between rights and obligations. Employers and employees are subjects of social insurances, by which the foundations created are important sources of fiscal appropriations in China's social security system. Based on international experiences and rules that international insurance system shall cover all groups, it may be inferred that the coverage of China's social insurances will be also further expanded with the constant development of social economy. Hence, the ranking of provinces in this aspect is generally in accordance with the final ranking for the level of social security.

\section{(2) Expenditures in Social Security and Economic Development}

Since social security is an economic means for solving social problems of China, a material basis and a financial security system are indispensable for supporting its development. At present, the funds invested in social security are mostly public funds in China, so the ratio of expenditures for social security to GDP, ratio of expenditures for social security to fiscal expenditures and ratio of educational expenditure to regional fiscal expenditures are found to bear a high load on the second principal component. Beijing and Shanghai rank top 2, while Guizhou, Jiangxi and Guangxi are ranked the last. From this ranking, it may be known that there are still certain gaps between top 2 cities and the latter provinces, which may generally reflect their gaps in their level of economic development. It is noteworthy that provinces such as Qinghai and Inner Mongolia rank top in the second principal component although they are not economically developed, mainly because their sparse population, wide area, limited and small number of participants in social insurances and availability of annual subsidies from transfer payments by the Ministry of Finance are quite effective for improving social security of these areas.

\section{(3) Factors of Population Ageing}

Related research has suggested that China has been in a stage of fast population ageing, which is expected to reach a peak by 2040 or so. Population policies that have always aimed to control population have not only made tremendous achievements in reducing population and promoting economic development, but also facilitated population ageing and miniaturization of families, thus posing great challenges to social security system. The dependency ratio of elderly population has a high load on the third principal component, which suggests that this ratio has been increasing in some provinces with the constant decline of birth rate, aggravation of population ageing and decline of birth rate. As a consequence, there have been growing demands for old age security systems, and the level of social security is thereby influenced. In terms of the third principal component, provinces such as Liaoning and Jiangsu are not ranked high, which indicates that population ageing has negative impacts upon development of social security in these areas.

\section{(4) Level of Social Security Benefits}

Mutual-aid principles are critical for supporting payment-based social insurances and other social security systems. From the perspective of theories and practices, social security system, in essence, is a risk-sharing and mutual aid mechanism with welfare characteristics. For instance, risks of life such as poverty, diseases, old age and disasters are neither totally tolerable for individuals nor completely assumed by governments. Instead, they are inseparable from arrangements of social security systems, which are mainly made for mutual aids among population covered by the systems. On the fourth principal component, urban expenditure per capita for minimum living standard, rural expenditure per capita for minimum living standard, rural expenditure per capita for five insurances and expenditure per capita for medical assistance bear high load, which suggests that reliefs and assistances of social security are integral parts of social security systems.

\section{Discussions}

Owing to areas' gaps in development and level of social security in China, imbalance is found among eastern, central and western China and within these areas, where the level of social security tends to be "high in both sides and low in the middle", which indicates that the development of social security 
is "fragmented" in China. In view that areas differ from each other in conditions of economic development, demographic situation, income level and cultural traditions, it is inevitable that a social security policy yields distinctive results in different areas. Therefore, governments shall establish policies for social security according to local conditions and formulate pertinent policies suitable for specific areas, in order to stimulate residents' consumption in areas with backward economic or social development, increase human capital stocks of backward regions, maximize effects of policies for social security and optimize allocation of social security funds, which is of great realistic significance for promoting economic growth of central/western China, coordinating regional economic development and narrowing regional differences.

At present, China is in a stage of transformation when gaps in level of social security are unavoidable among and within provinces. Furthermore, population of middle and western China largely migrates to developed areas of eastern China, including Yangtze River Delta and Pearl River Delta. Nevertheless, their evaluation of indexes for social security is not proportional to their actual financial strength, and influx of much migrant population is an important factor that impacts level of social security. Hence, efforts shall be made to increase and improve infrastructures and social service facilities with the influx of labor forces. On the premise of considering migrant population's differences in status, it is necessary to improve related laws, rules and regulations while improving and regulating policies about population structures, politics, investments and industries, so as to narrow provinces' gaps in level of social security and comprehensively improve social security in a balanced manner.

\section{Acknowledgement}

This research was financially supported by the Scientific Research Project of Guangdong University of Foreign Studies, South China Business College (17-007A).

\section{References}

[1] J. Feldstein M. The Optimal Level of Social Security Benefits[J]. Quarterly Journal of Economics, 1982, 100(2):303-320.

[2] Bellettini G, Ceroni C B. Social security expenditure and economic growth: an empirical assessment[J]. Research in Economics, 2000, 54(3):249-275.

[3] HE Yan-zi, WANG Huan-fang, LIU Jia-wen. An Empirical Analysis of Regional Economic

Development Differentiation in Chinese Eastern, Middle and Western Regions[J]. Journal of Nanchang Hangkong University (Social Sciences),2016, 18(3):48-54.(In Chinese).

[4] Jin J, Xu K, Xiong N, et al. Multi-index evaluation algorithm based on principal component analysis for node importance in complex networks[J]. Networks Iet, 2012, 1(3):108-115.

[5] Li C Q, Li C Y, Jin X B, et al. Evaluation on the Ability of Regional Sustainable Development Based on the Principal Component Analysis: A Case Study of Jiangsu Province, China[C] International Conference on Management and Service Science. IEEE, 2009:1-4. 